Mollaw Abraha'

Department of Pedagogical Science;

Woldia University - Ethiopia
Original scientific paper

UDC: 37.013

DOI: $10.5937 /$ IstrPed2002162A

\title{
EDUCATIONAL OBJECTIVES HELP OR HINDRANCE? A REFLECTION AGAINST THE POSITION OF EISNER
}

\begin{abstract}
Although educational objectives have played critical roles in facilitating instructional activities easily, Elliot W. Eisner argued against this by saying that the pre-intended objectives have hindered the practitioners' instructional initiatives. Not only Eisner but also other re-conceptualists and conceptual empiricists viewed the objectives negatively. In one way, they may be right in which the procedural approach may not seem to allow curriculum makers to exercise curricular issues holistically. On the other way, it is difficult to manage the broad curricular issues in a real environment since running the teaching-learning activities is problematic if the instruction is boundless. Though both the conceptual empiricists and reconceptualists have criticized the traditional approaches of curriculum, they couldn't show their ways of exercising curriculum practically in the real world, i.e., their ideas simply remain on the paper. Still now, conceptions of the traditionalists are influential around the world early from kindergarten up to the higher education level than the opponents' impractical propaganda. Therefore, educational objectives remain helpful rather than impediment not only for this century but also for the coming centuries.
\end{abstract}

Keywords: - Education, Empiricist, Help, Hindrance, Objective, Re-conceptualist, Traditionalist.

\section{Introduction}

Traditionalists, particularly R. Tyler dictated that it is vital to follow linear steps to facilitate curriculum leading from the formulation of goals and specification of outcomes. Identification of classroom experiences presumed to yield desired outcomes, and precise articulation of evaluation procedures to measure achievement or non-achievement of the specified goals. Alternatively, as a planned program, the curriculum has four elements: objectives, contents or subject matters, learning experiences, and evaluation (Pinar, 1978). The predetermined behavioral objective serves as a driving force that controls the pedagogical and evaluative efforts that follow. Tyler asserts that the development of objective is necessarily the first step in curriculum planning because it is the most critical criterion for guiding all the other activities of the curriculum maker (Laanemets and Kalamees, 2013). As a result, of the stated elements of the curriculum, I tried to review the stated impressions of Eisner on whether educational objectives - help or hind?

\footnotetext{
1 (mollawabrahaog@gmail.com)
} 


\section{R. Tyler's Educational Objectives}

The purpose of education is to prepare the learner for citizenship and stewardship in their local and global community. Educational learning outcomes designed for this end should emphasize interconnectedness in the relationships with others and responsibility for the environmental health and social justice for the present and future generations (Armstrong and LeHew, 2011). As Eisner $(1967,2002)$ argued, educational objective needs to be specified at least for the three reasons: it provides the goals towards which the curriculum is aimed at; it facilitates the selection and organization of content, and it makes possible opportunities to evaluate the outcomes of the curriculum if the objective is stated in both behavioral and content terms.

However, Eisner $(1967,2002)$ argued that the pre-intended educational objective has hampered the curricular activities since it has the following limitations:

To begin with, educational objectives can predict the outcome of the instructional process. Yet, the outputs of the instruction are far more numerous and complex for educational objectives to encompass: the amount, type, and quality of learning that occurred in the classroom, especially when there is an interaction among students, are only in small part predictable. The changes in pace, tempo, and goals that experienced teachers employ when necessary, and appropriate for maintaining classroom organization are dynamic rather than mechanistic (Eisner, 1967, 2002).

Based on Eisner's contentions, prediction of the outcome of the instructional process is a drawback of the educational objectives. However, to the reviewer, it is not such a shortcoming because unless we envisage what will happen in the future, it is complicated to manage curricular activities. Forecasting what the practitioners are going to achieve for the next permits them to define and make their journey to be directional. It is clear how the instructional environment is full of complexities and varied that may influence the roles of teachers or curricular makers if they try to play their activities without delimiting the required instructional destination.

Consequently, to manage such educational intricacies and disparities, the pre-determined path is mandatory to determine the types of activities to be done and identify the required resource materials for the stated instructional activities in terms of human and material resources. It also helps curriculum implementers to make a follow up about how the given activity is facilitated, etc. To this point, Mahajan and Kaur (2017, PP.65) expressed their intention in this way:

Educational objectives are like navigational tools, such as Global Positioning System (GPS). Once the destination is fed to the GPS, the device guides the driver throughout the journey and takes him to the mentioned destination correctly without fear of losing the way. Even if the motorist takes the wrong route, the GPS guides and helps him to join the route which leads to the intended purpose. Similarly, educational objectives are guiding tools that direct students to the desired results of the planned course. They also assist and show teachers the path to follow and make students aware of what they will be able to achieve at the end of the course. Also, they help teachers and students know the route to follow.

Therefore, according to the reviewer, advantages of educational objective weighted than its drawbacks because knowing the goals or objectives of a course can help students monitor 
their progress. To become self-directed learners, students must learn to assess the demands of the task; evaluate their knowledge and skills; plan their approach; monitor their progress, and adjust their strategies as needed (Kruger and Dunning, 1999). When learning objectives are undefined or not clear, students cannot tell what type of knowledge they should be developing. Faced with this ambiguity, students naturally interpret their learning goal in terms of the "easier" level/type of knowledge, which may be rather different from what the instructor intends to.

In general, learning objectives are essential to have a strong foundation in the development of learning materials. Specifically, the objectives provide clarity about the purpose of the course; guide the development of appropriate content, methods, and materials by the curriculum developer to facilitate learning and meet teaching goals. The objectives also establish accountability between the learner and instructor, and help teachers to articulate exactly what they want participants to do by the end of the instructional processes (International Training and Education Center for Health, 2010).

The second limitation of educational objectives is its failure to realize the constraints face on the various subject matters which emanated from the objectives. This means theory concerning educational objectives did not consider the particular relationship holds between the subject matter being taught, and the degree to which the instructional objectives are predicted and specified. The reason is that some curriculum experts have high degrees of intimacy with ranges of subject matters, and motivate to modify their general theoretical views to suit the demands of the particularly organized instructional concepts (Eisner, 1967, 2002).

However, there are stated approaches, models, or principles set by the traditionalists that allow the practitioners to tackle such types of challenges. Explicitly, a useful framework for all curriculum stakeholders is the use of the concept of an 'Academic Plan', which focuses on the planning process. This includes elements such as purposes, content, sequence, instructional processes, instructional resources, evaluation, and adjustment. Lack of shared understanding of the term 'curriculum' can be problematic when staff gathers together to do the shared curriculum design activities (O’ Neill, 2015).

Integration is one of the aspects of curriculum organization that shows how the related curricular issues would be integrated into each subject instead of organizing contents based on the experts' proximity of the particular subject matters. According to Tyler (1949), curriculum development is a matter of carrying out some activities though the procedure may vary depending on the nature of tasks. The field of curriculum, as Tyler (1949) stated, should be emphasized on the approaches of curriculum development as there are adequate models that address various needs of diverse institutions. An approach refers to the various aspects of the development process, procedures, and participants in curriculum development projects.

From this argument, anyone can understand that though various issues are incorporated in curricular area, approaches, models, and procedures, etc. can be used as devices to tackle the faced problems as mentioned by the Eisner above. Therefore, the main problem may not be more from educational objectives rather the lack of using such stated strategies in the curricular issues accordingly. 
The third limitation indicated by Eisner $(1967,2002)$ was the objectives stated in the behavioral and content terms are used as the criteria to measure the outcomes of curriculum and instruction. According to him, all outcomes of the curriculum and instruction could not be amenable to measurement. Therefore, as Eisner argued, the evaluation must be made, not primarily by applying a socially defined standard, but by making human qualitative judgments. He also added that making of judgment in distinction to the application of a standard assessment implies how the valued qualities are not just socially defined and arbitrary.

However, to me, the problem may occur at the side of the evaluator but may not from an objective aspect because the pre-intended objectives enable us to see multidimensional approaches to achieve the output. As we have varieties of opportunities that supported us to reach in the output stage, there are also varied types of evaluation mechanisms that assisted us to investigate the overall curricular activities. Likewise, International Training and Education Center for Health (ITECH) (2010) disclosed that questionnaires, surveys, interviews, observations, tests, and participant portfolios of ongoing work, etc. are considered as some of the most common evaluation methods. These strategies, as the ITECH (2010) added, should be incorporated into the learning experience so that both the learners and teachers know if the learning objectives have been met.

In another way, instructional objectives are identified as the goals that one, as a teacher, aims at while teaching. On the one hand, they provide direction for planning appropriate instruction, and, on the other hand, they provide a basis for determining whether one has achieved what one has set out to accomplish - they provide criteria for assessing the outcomes of one's teaching. When identifying objectives to use in classroom assessment and evaluation, it is important to use those objectives that best describe what one, as an individual teacher, wants to accomplish (Jabbarifar, 2009).

Therefore, in my opinion, the problems may arise from the evaluator's shortage of evaluation application skills, lacks commitment to conducting varieties of assessment techniques, etc. Or the challenges may results from the sides of the given institution in terms of scarcities of the required resource materials, lack of providing training opportunity for teachers or evaluators, etc. Moreover, conducting evaluation qualitatively or subjectively is difficult to measure the real output since it might be personal, i.e., one thing may seem to be acceptable for one individual may not be for the other. Likewise, Tyler (1949) stated that it is difficult to refute the validity of the broader definitions of curriculum at the evaluation stage of the curriculum implementation process. Certainly, the experiences that students have under the auspices of the school comprise valuable data for assessing the quality and effectiveness of the planned curriculum.

Thus, effective instructional assessment and evaluation requires an understanding of the roles of evaluation in the planning and delivering lessons. It calls for the collection and interpretation of ranges of subject matters; it needs familiarity with a variety of different methods of assessment, and for competence in using these methods creatively, careful and systematic record-keeping, and judgment. The successful assessment and evaluation also call on teachers to become agents of change in their classrooms actively using the results of measurement to modify and improve learning environments they create (Jabbarifar, 2009). Therefore, educational objectives may not be problematic by themselves which hinder assessment practices of curriculum makers. 
Eisner $(1967,2002)$ also stated the fourth limitation as an educational objective need not be preceded the selection and organization of the content because curriculum development usefully constitutes an empirical problem, and imposing the logical requirements up on the process is an error. Therefore, according to him, curriculum theory has to allow ranges of processes to be employed in the construction of the curriculum.

However, it is difficult to accept the argumentative issues of Eisner because it is clear how contents are strategies used to achieve the pre-intended objectives (Jabbarifar, 2009). To realize this, the subject matters have to stem from the designed objectives and need to be organized. Moreover, to manage the curricular issues easily, a curriculum boundary is mandatory since it defines the schools' instructional activities.

Related to this, proponents of the Tylerian tradition proposed that the demarcation of the field defines the field. The curriculum field needs to identify those phenomena considered in the domain of curriculum inquiry. These phenomena should be limited largely to matters about the life and program of the school (Dawit, 2008). This, as Orinsten \& Hunkins (2009) argued, means the curriculum must address children's interests, social functions, and organized knowledge. It should provide the proper scope and sequence of the subject matter at every grade level. Thus, the content should match the social functions, and learners' interests and the knowledge obtained should be measured.

Generally, unless the curriculum activities are procedural and scope based, it is complex to facilitate the instructional activities practically in the real context. That is why Tyler's model has remained convenient to apply in all learning areas and levels. Besides, it is easy to find the appropriateness of content, activities, assessment techniques, and teaching methods based on the stated objectives. Thus, the sequence of curriculum elements is logical, and the model is useful for easily forecasting the final instructional outcomes (Chen, Chen \& Cheng, 1996; Brady \& Kennedy, 2010, cited in Cruickshank, 2018).

\section{Conclusion}

Although the Tylerian educational objectives have played pivotal roles in facilitating the educational activities, Eisner $(1967,2002)$ argued inversely as the pre-intended objectives have stalled the instructional practicing initiatives of the practitioners. Not only Eisner but also reconceptualists and conceptual empiricists have viewed the mechanistic approach of the curriculum negatively. In one way, they may be true in which the technical approach might not allow the practitioners to manipulate the curricular issues holistically, but it is difficult to put the instructional issues into practice if the curriculum is boundless.

Even though the Tylerian opponents argued strongly on how the traditional approach is ineffective to practice the curricular issues, they couldn't indicate alternative strategies to exercise the instructional activities practically as traditionalists have done. This means their ideas have remained on paper. As we know, the ideas of traditionalists are dominant in the world early from the kindergarten to the higher education level than the adversary's impractical propagandas.

Therefore, based on the reviewer's opinion, educational objectives remain helpful rather than being hindrance not only in this century but also for the coming more centuries since its elegant simplicity of facilitating the instructional activities. Equally, Cruickshank (2018) argued 
that despite the criticism of the model, Tyler's thinking continues to be popular, and his concepts of behavioral objectives, curricular organization, and evaluation are deeply embedded in the standards and accountability movement of the present day. According to Moosa (2015), the traditionalist perspective is still relevant to curriculum studies in South Africa due to curriculum changes, which have taken place in the post-Apartheid era. The major reason for the continued influence of the Tyler rationale is due to its close similarities to societal expectations for schooling and curriculum planning. These expectations or assumptions include schools being places of learning, development of objectives in terms of desired learning, and defining of curriculum concerning the desired learning outcomes (Meyer and Apple (1998, cited in Cruickshank, 2018).

Generally, the Tyler Rationale has provided general scaffolding for the process and is particularly useful for the development of learning outcomes instead of influencing negatively the instructional motives of the practitioners (Armstrong and LeHew, 2011).

\section{References}

Armstrong, C. \& LeHew, M. (2011). Scrutinizing the Explicit, the Implicit and the Unsustainable: A Model for Holistic Transformation of a Course for Sustainability. Journal of Teacher Education for Sustainability, 13 (2): pp. 17-43.

Cruickshank, V. (2018). Considering Tyler's Curriculum Model in Health and Physical Education. Journal of Education and Educational Development, 5(1).

Dawit Mekonnen (2008). Theories of Curriculum. Unpublished, Bahir Dar University.

Eisner, E. W. (1967) Educational Objectives: Help or Hindrance? American Journal of Education, $91(4):$ pp. $549-560$.

Eisner, E. W. (2002). The arts and the creation of mind. New Haven, CT: Yale University Press.

International Training and Education Center for Health (2010). Writing Good Learning Objectives. Technical Implementation Guide, No. 4.

Jabbarifar, T. (2009). The Importance of Classroom Assessment and Evaluation in Educational System. Proceedings of the $2^{\text {nd }}$ International Conference of Teaching and Learning (ICTL) INTI University College, Malaysia.

Kruger, J. \& Dunning, D. (1999). Unskilled and Unaware of It: How Difficulties in Recognizing One's Own Incompetence Lead to Inflated Self-Assessments. Journal of Personality and Social Psychology, 77 (6): 121-1134.

Laanemets, U. \& Kalamees, K. (2013). The Taba-Tyler Rationales. Journal of the American Association for the Advancement of Curriculum Studies - Volume 9.

Mahajan, M. \& Kaur, M. (2017). Importance and Benefits of Learning Outcomes. IOSR Journal of Humanities and Social Science (IOSR-JHSS), 22(3): PP 65-67.

Moosa, R. (2015). The Nature of Curriculum Studies Scholarship in South Africa: 2008 - 2010. Unpublished MA Thesis, University of the Witwatersrand, Johannesburg.

O'Neill, G. (2015). Curriculum Design in Higher Education: Theory to Practice, Dublin: UCD Teaching \& Learning. Available at http://www.ucd.ie/t4cms/UCDTLP0068.pdf.

Ornstein,A.C. \& Hunkins, F.R. (2004) Curriculum: foundations, principles and issues. PEARSON.

Pinar, W. F. (1978). The reconceptualization of curriculum studies. Journal of Curriculum Studies, 10, 205-214.

Tyler, R. (1949). Basic principles of curriculum and instruction. Chicago, IL: University of Chicago Press. 


\section{Biographical notes:}

Mollaw Abraha completed his First Degree in Pedagogical Sciences Composite English, and Master's Degree in Curriculum Studies both from Bahir Dar University, Ethiopia. He had been worked as an elementary school teacher and a supervisor, and a high school teacher for 9 years. Moreover, he has been teaching at Woldia University for the last 3 years. He is now a PhD student in Bahir Dar University in Curriculum and Instruction. 